\title{
Protogenin, a new member of the immunoglobulin superfamily, is implicated in the development of the mouse lower first molar
}

\author{
Keiko F Takahashi ${ }^{1 \dagger}$, Tamotsu Kiyoshima ${ }^{1 \dagger}$, leyoshi Kobayashi ${ }^{1}$, Ming Xie ${ }^{2}$, Haruyoshi Yamaza ${ }^{3}$, Hiroaki Fujiwara', \\ Yukiko Ookuma ${ }^{1,3}$, Kengo Nagata', Hiroko Wada', Takako Sakai ${ }^{4}$, Yoshihiro Terada ${ }^{4}$, Hidetaka Sakai ${ }^{*}$
}

\begin{abstract}
Background: Protogenin (Prtg) has been identified as a gene which is highly expressed in the mouse mandible at embryonic day 10.5 (E10.5) by a CDNA subtraction method between mandibles at E10.5 and E12.0. Prtg is a new member of the deleted in colorectal carcinoma (DCC) family, which is composed of DCC, Neogenin, Punc and Nope. Although these members play an important role in the development of the embryonic central nervous system, recent research has also shed on the non-neuronal organization. However, very little is known regarding the fetal requirement of the non-neuronal organization for Prtg and how this may be associated with the tooth germ development. This study examined the functional implications of Prtg in the developing tooth germ of the mouse lower first molar.

Results: Ptrg is preferentially expressed in the early stage of organogenesis. Prtg mRNA and protein were widely expressed in the mesenchymal cells in the mandible at E10.5. The oral epithelial cells were also positive for Prtg. The expression intensity of Prtg after E12.0 was markedly reduced in the mesenchymal cells of the mandible, and was restricted to the area where the tooth bud was likely to be formed. Signals were also observed in the epithelial cells of the tooth germ. Weak signals were observed in the inner enamel epithelial cells at E16.0 and E18.0. An inhibition assay using a hemagglutinating virus of Japan-liposome containing Prtg antisensephosphorothioated-oligodeoxynucleotide (AS-S-ODN) in cultured mandibles at E10.5 showed a significant growth inhibition in the tooth germ. The relationship between Prtg and the odontogenesis-related genes was examined in mouse E10.5 mandible, and we verified that the Bmp-4 expression had significantly been decreased in the mouse E10.5 mandible $24 \mathrm{hr}$ after treatment with Prtg AS-S-ODN.

Conclusion: These results indicated that the Prtg might be related to the initial morphogenesis of the tooth germ leading to the differentiation of the inner enamel epithelial cells in the mouse lower first molar. A better understanding of the Prtg function might thus play a critical role in revealing a precious mechanism in tooth germ development.
\end{abstract}

\section{Background}

The organs of vertebrates are typically composed of epithelial and mesenchymal tissues. Signaling between these two tissues governs many aspects of organogenesis, from the initiation of organ development to the terminal differentiation of organ-specific cell types. The

\footnotetext{
* Correspondence: hsakaiop@dent.kyushu-u.ac.jp

† Contributed equally

'Laboratory of Oral Pathology and Medicine, Faculty of Dental Science, Kyushu University, Fukuoka 812-8582, Japan

Full list of author information is available at the end of the article
}

development and differentiation of the mouse tooth germ, like many other organs, depends on such inductive interactions. A large number of genes have been proven to be related to tooth morphogenesis [1-8]. However, the precise signaling pathway which is involved in the initiation, growth, and differentiation of the tooth germ has not yet been fully elucidated. There may be additional odontogenesis-related genes that have not yet been identified. A cDNA subtraction between the mandibles of embryonic day 10.5 (E10.5) and E12.0 mice was conducted to identify genes which might be

\section{Biomed Central}


related to the tooth morphogenesis. Thirty-five of the highly expressed positive clones were obtained from the E10.5 mandible by a colony array screening. In addition, 47 of the highly expressed positive clones were also obtained from the E12.0 mandible [9]. The expression of several of those genes is closely associated with the developing tooth germ [7,8,10-12]. Protogenin (Prtg) $[13,14]$, which we first designated as Clone 15 , is one of the highly expressed genes in the mouse mandible at E10.5 [9].

Prtg belongs to the immunoglobulin superfamily (IgSF), which is one of the largest protein families in the mammalian genome $[15,16]$. This family is comprised of transmembrane and cell surface proteins and its members are characterized by immunoglobulin (Ig) domains in their extracellular regions. The IgSF members act as adhesion molecules, and can also transduce signals upon ligand stimulation. Many members of the IgSF are involved in tissue formation and morphogenesis during embryonic development $[15,16]$. However, thus far the functions of Prtg have not been elucidated.

The constituents of a subgroup of the IgSF have recently received attention because of their roles in the migration and guidance of axon growth during development of the vertebrate nervous system. One of the representative genes in this subgroup is the Deleted in Colorectal Cancer (DCC) gene, and therefore this subgroup is referred to DEAL (DCC et al.), and includes DCC, Neogenin [17], Punc [18], and Nope [19]. DCC was originally identified as a tumor suppresser gene [20], but it has been recently shown to act as a Netrin receptor for cell migration and axon guidance cues [19]. Like DCC, Neogenin is a Netrin receptor. Punc [21] and Nope are prominently expressed by differentiating neurons in the central nervous system. They are involved in the early stages of nerve tissue morphogenesis. Prtg belongs to DEAL because their structures are highly homologous. There are two reports in which the expression of Prtg was described in chick [13], mouse, and zebrafish [14]. These reports demonstrated that Prtg is expressed in the central nervous system in the early developmental stages of the embryo. Vesque et al. [14] demonstrated that this gene is expressed in the first branchial arch as well as in the central nervous system. This finding supported a previous study [9] in which Prtg was preferentially expressed in the first branchial arch prior to tooth germ formation. Therefore, it is possible that the Prtg gene is related to the morphogenesis of the tooth germ because the tooth germ develops under the influence of cells in the first branchial arch. This study characterized the expression pattern of Prtg in the developing tooth germ, and examines the possible functional implications of this gene in tooth germ morphogenesis.

\section{Results}

\section{Characterization of predicted Prtg protein}

A DNA sequence analysis was performed by using of the 5'-RACE and 3'-RACE methods. Based on the DNA sequence analysis, the Prtg protein comprises 1191 amino acids, a signal peptide (SP), 4 Ig domains, 5 fibronectin (FN)-type III repeats, a single transmembrane (TM), and a cytoplasmic domain (CD). The deduced molecular structure is shown in Figure 1. In sequencing the five independent Prtg cDNA clones from E10.5 mice, no alternatively spliced variant was found within the coding region of the amino acids.

Full-length (Prtg-full) cDNA and mutant cDNA with a complete deletion of the SP region were inserted into an enhanced green fluorescent protein (EGFP) (Clontech) vector, and was then transfected into MISK81-5 cells, which is an oral squamous cell carcinoma cell line established in our laboratory [22], to characterize the intracellular localization of the Prtg protein. The MISK81-5 cells transfected with Prtg-full showed a localization of EGFP-fusion protein in the cell membrane by fluorescence microscopy (Figure 2B). Meanwhile, the other transfectants with Ptrg- $\Delta S P 1$, Prtg- $\Delta S P 2$, or empty vector showed a diffuse intracellular Prtg distribution (Figure 2B). Immunofluorescent staining for cadherin, a marker of the cell membrane-associated protein, in the transfectants with Prtg-full showed that the fluorescence images of Prtg-EGFP fusion protein and cadherin were merged (Figure $2 \mathrm{C}$ ). These results indicated that Prtg was localized in the cell membrane.

A Western blot analysis using a Prtg affinity polyclonal anti-body demonstrated the molecular mass $(M r)$ of Prtg to be $180 \mathrm{kDa}$ (Figure 3, lane 2). The mature

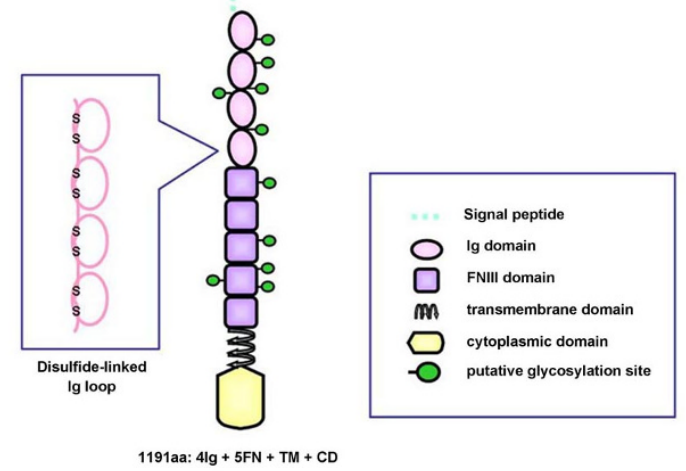

Figure 1 Prtg has a characteristic domain structure and putative glycosylation sites in the extracellular region. The Prtg protein contains a signal peptide, Ig domains, five fibronectin-type III (FNIII) repeats, a single transmembrane (TM), and a cytoplasmic domain (CD). The structure indicates a high similarity to Nope. The circles indicate glycosylated sites. 


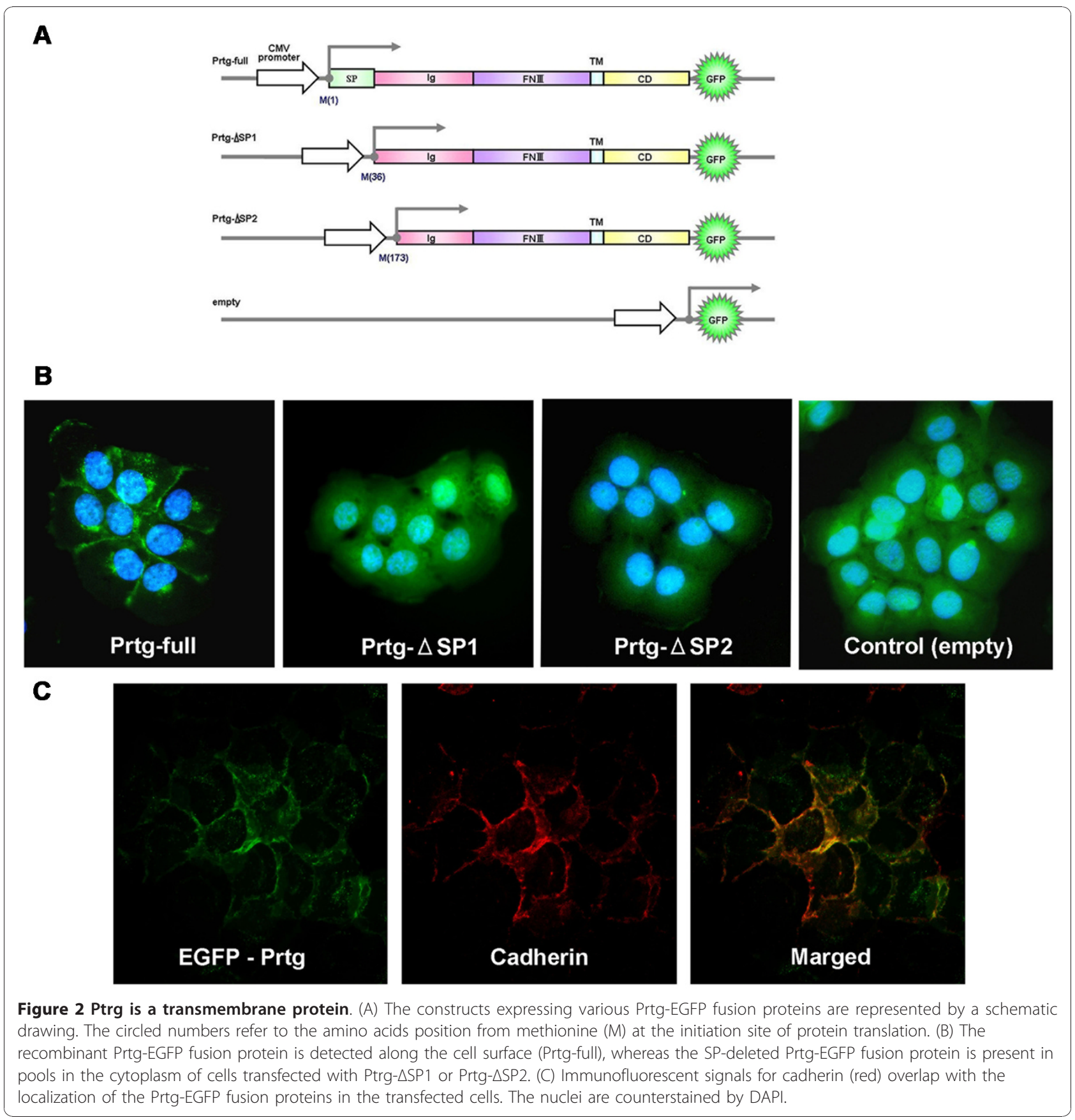

mouse Prtg contains 1191 amino acids, and therefore the estimated $M r$ is approximately $130 \mathrm{kDa}$. Because the molecules which have SP in the extracellular domain (ECD) are often highly glycosylated, it is thought that differences in $M r$ might be caused by glycosylation at the ECD (Figure 1). Prtg protein was purified from the mandible at E10.5, and was treated with $\mathrm{N}$-glycosidase $\mathrm{F}$ and assayed by an immunoblotting analysis to confirm ECD glycosylation and to identify the accurate size of Prtg. A Western blot analysis after the treatment of
N-glycosidase F showed a reduced Prtg size (Figure 3, lane 3).

Temporal expression analysis of Prtg mRNA and protein during odontogenesis

Because Prtg was highly expressed in the mouse mandible at E10.5 [9], the temporal expression pattern of the Prtg mRNA during embryogenesis was examined by semiquantitative RT-PCR with the total RNA from whole embryos. Prtg is highly expressed at E10.5 (Figure 4A). 


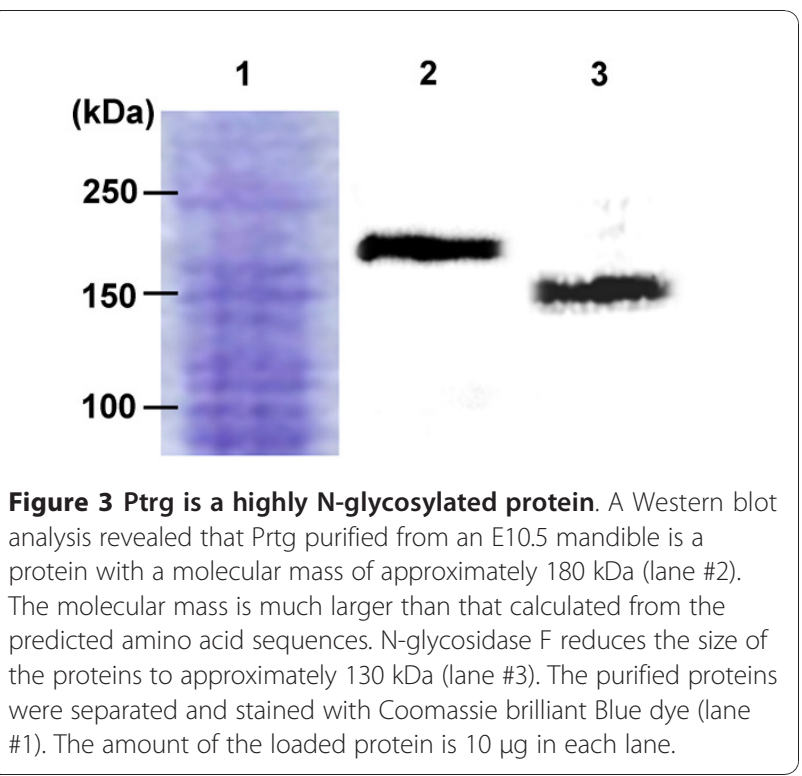

However, there were considerable decreases in the level of mRNA in the whole body at E14.0 and E18.0 (Figure 4A). Thereafter, the Prtg mRNA expression was examined in adult organs, and compared to the expression level of the E10.5 embryo. A weak expression was demonstrated in the central nervous system of the adult mice. Meanwhile, no expression was detected in the other organs (Figure 4B). These results indicated that Prtg mRNA is primarily expressed at the early-middle stages of embryogenesis $[13,14]$.

The expression level of Prtg protein in the mouse mandible was also examined by a Western blotting analysis. As shown in Figure 4C, the Prtg protein levels in the mandible were higher at E10.5 than that at E12.0. The Prtg mRNA levels also decrease in the E12.0 mandible compared to the E10.5 mandible in the cDNA subtraction analysis [9]. The expression level of the Prtg protein was dramatically reduced in the tooth germ at E18.0 (Figure 4C).

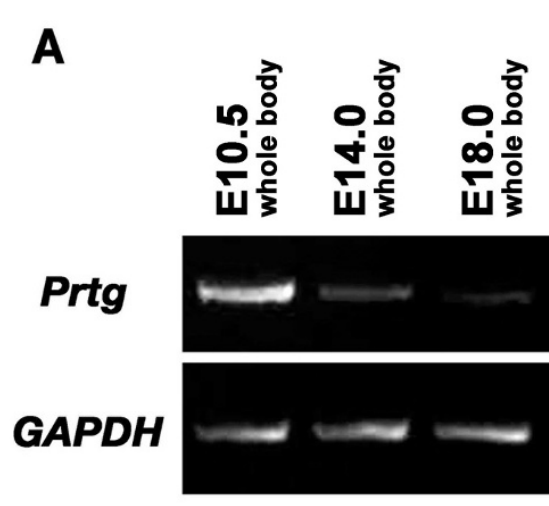

C
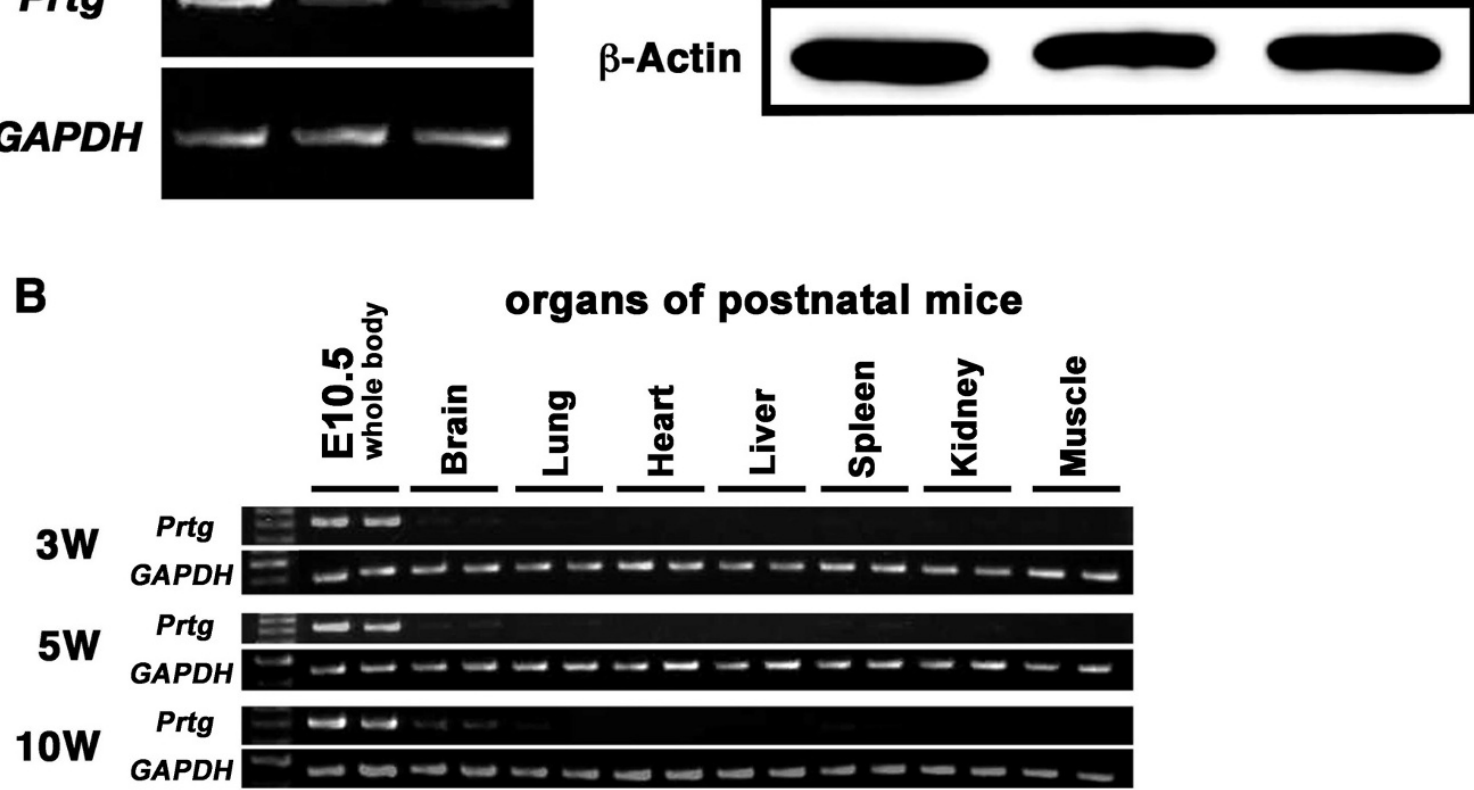

Figure 4 Prtg is preferentially expressed in the early stage of organogenesis. A semi-quantitative RT-PCR analysis of Prtg is compared at various embryonic stages and in various organs of postnatal mice. (A) As development proceeded from E10.5 to E14.0, the Prtg transcripts were dramatically decreased in the whole body. (B) In the postnatal mice, Prtg transcripts were detected only in the brain of the 10-week-old mice. However, they were remarkably reduced in comparison with that in the E10.5 whole body. Each organ group is represented by two samples. (C) According to an immunoblotting analysis, Prtg is expressed at substantially higher levels in the E10.5 mandible than in the E12.0 mandible. Prtg was dramatically decreased in the tooth germ at E18.0. The amount of the loaded protein is $10 \mu \mathrm{g}$ in each lane. 


\section{Expression of the Prtg mRNA and protein in the} developing tooth germ and other organs

An in situ hybridization analysis was performed by using a Prtg antisense cRNA probe to examine the temporal and spatial expression pattern of the Prtg mRNA in the course of the developing mouse embryonal organs. In situ hybridization (ISH) for Prtg mRNA showed diverse signal intensity within the same tissue section. Therefore, the terms "strong" and "weak" were used only for the relative evaluation of the signal intensity in the same section.

The whole mount in situ expression of the Prtg mRNA at E10.5 revealed that this signal was present in the maxilla and mandible as well as central nervous system and eye, and thus the expression pattern of Prtg mRNA seemed to correspond to the distribution of the arch ectodermal cells (Figures 5A and 5B). This appeared to be similar to the results of the study by Vesque et al. [14]. In addition, in the study by Chai et al. [23], the Prtg function appeared to be involved in the cranial neural crest cells. At E10.5, a strong expression of in situ signal of Prtg was seen in the mesenchymal cells which were widely distributed in the first branchial arch including the developing mandible (Figure 5C). A signal was also found throughout the oral epithelial layer. At E12.0, in situ signal was observed in the oral epithelial layer, including the thickened area and underlying mesenchymal cells (Figure 5D). At E14.0, the Prtg mRNA signal was rather restricted to the enamel organ and the dental mesenchyme (Figure 5F). At E16.0, in situ signal of Prtg was detected in the enamel organ, in the dental papilla and in the dental sac (Figure 5G), but the intensity appeared to be reduced. At E18.0, a faint in situ signal of Prtg was found in the inner enamel epithelium. The faintly positive cells were localized in the presumptive cuspal areas. Weak mRNA expression was also observed in the outer enamel epithelium. However, the in situ signal was markedly reduced in the dental papilla (Figure 5H). A Prtg sense probe was applied to the tissue specimens as a control. However, no hybridization signal was detected (Figures 5E and 5I).

An immunohistochemical analysis (IHC) was also carried out using an anti-Prtg antibody. Both the protein expression and gene expression were detected in the first branchial arch in a widespread pattern, in both the epithelium and mesenchyme. Strong signals were noted near the oral epithelial layer (Figure 6A). A higher magnification showed the immunohistochemical signal of the Prtg protein to be observed surrounding the cells with a punctate appearance (Figure 6B), suggesting protein localization on the cell surface. This staining pattern was common in all the sections of each embryonic day. Although immunolocalization of the protein was present in both the epithelium and mesenchyme at
E12.0, the signal intensity was reduced in comparison to that at E10.5 (Figures 6C and 6D). At E14.0, the Prtg protein signal was conspicuously detected in the enamel organ and the surrounding condensed mesenchymal cells (Figures 6E and 6F). The signal in the epithelium was stronger than that in the mesenchyme. At E16.0, immunohistochemical signal of Prtg were marginally detected in the enamel organ and in the dental papilla (Figures 6G and 6H). At E18.0, a faint immunohistochemical signal was detected in the inner and outer enamel epithelia, and in the dental papilla (Figures 6I and $6 \mathrm{~J})$.

Thus, both the mRNA and protein of Prtg demonstrated similar expression patterns during odontogenesis. In addition, the expression of Prtg is localized in the developing nervous system, especially in the neural tube, the retina, the lens, and the brain throughout the embryonic period.

\section{Functional analysis of Prtg during development of the tooth germ}

The results of the in situ hybridization and immunohistochemical analyses suggested that Prtg might be involved in tooth morphogenesis. Therefore, an inhibition assay for the translation of Prtg mRNA was performed using Prtg antisense-phosphorothioated-oligodeoxynucleotide (AS-S-ODN) according to the same experimental design in our previous studies [6,7].

The expression of Prtg was time-dependently examined in the organ-cultured E10.5 mandibles because the expression level of Prtg markedly decreased after E12.0 in comparison to that at E10.5 (shown in the Figures 4A and $4 \mathrm{C}$ ). The real-time PCR showed a marked decrease of the Prtg expression by $48 \mathrm{hr}$ in mandible culture (Figure $7 \mathrm{~A}$ ) as well as that in E10.5 and E12.0 mandibles (Figure 7B). The Prtg expression in the mandibles cultured for $24 \mathrm{hr}$ and $48 \mathrm{hr}$ significantly decreased to less than $40 \%$ and $15 \%$ of that in the E10.5 mandible, respectively. The Prtg expression in the E12.0 mandible also showed a marked reduction to less than $5 \%$ of that in the E10.5 mandible.

A histological analysis was performed to evaluate the effects of Prtg knockdown on enamel organ formation in the cultured E10.5 mandible after phosphorothioatedoligodeoxynucleotide (S-ODN) treatment for 8 days. The period of organ culture was based on previous studies $[6,7]$ in which the normal development of the tooth germ showed the cap stage by the 8th day of organ culture. As shown in Table 1, most of the cultured mandibles at E10.5 treated with Prtg AS-S-ODN showed an apparent inhibition of tooth germ development after being cultured for 8 days (Figure 7D and Table 1). In contrast, the mandibles treated with Prtg sense-S-ODN (SE-S-ODN) showed normal cap-like tooth germ (Figure 7C) as did 


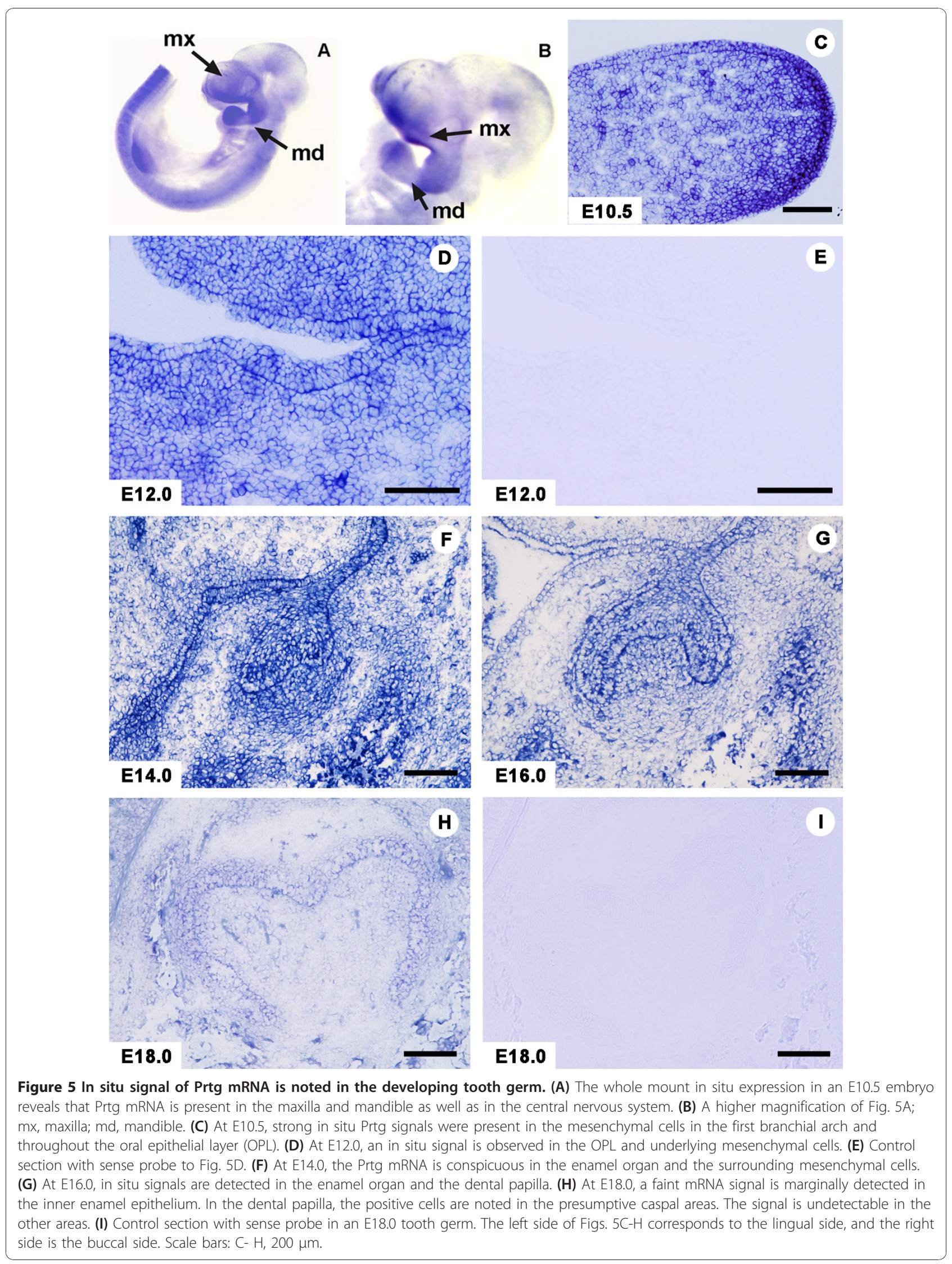



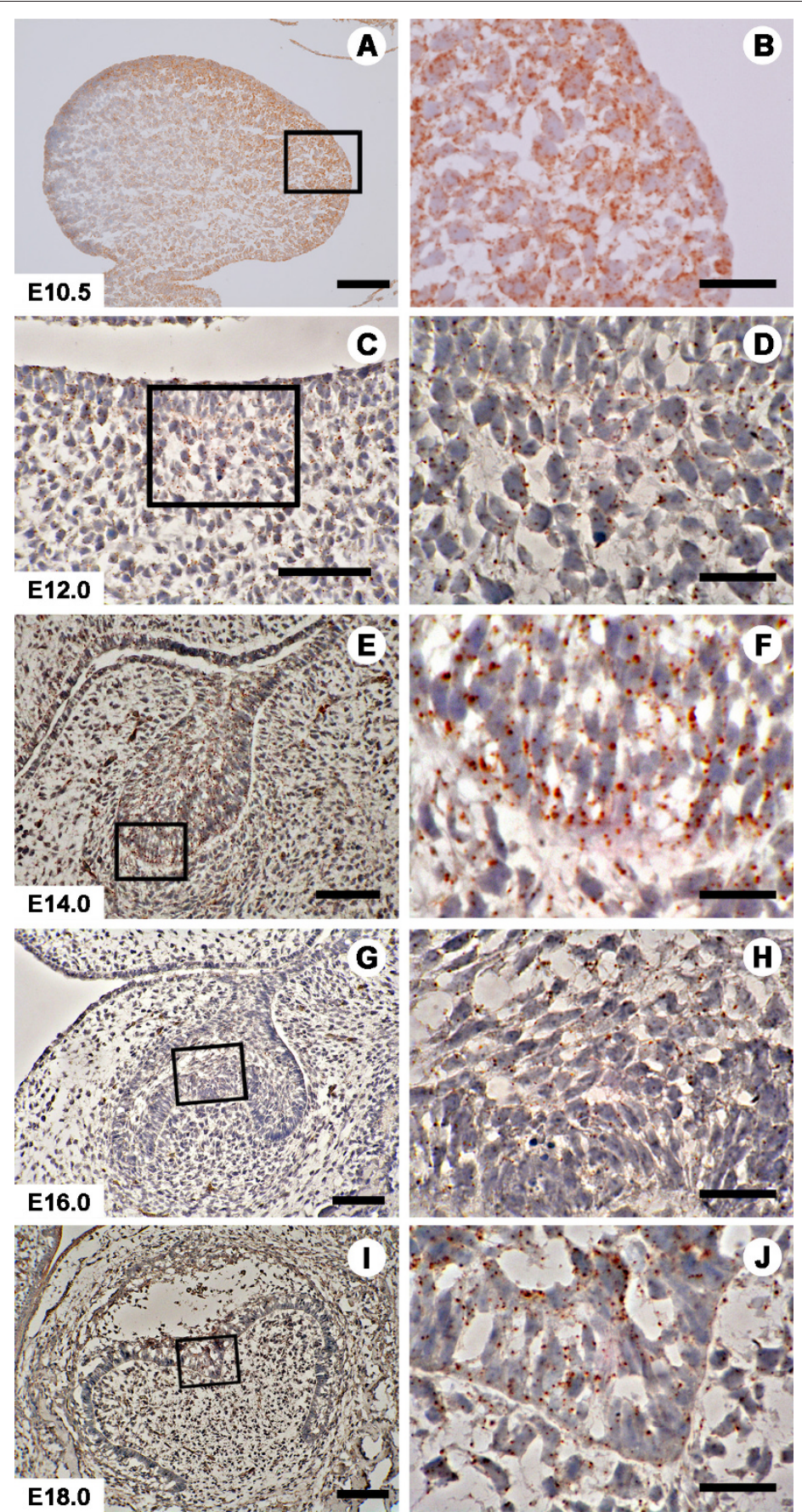

Figure 6 Immunohistochemical expression of Prtg is also observed in the developing tooth germ. (A) At E10.5, immunohistochemical Prtg signals were present in the mesenchymal cells in the first branchial arch and throughout the oral epithelial layer (OPL). (B) A higher magnification of Fig. 6A. The signal of the Prtg protein is localized around the cell, suggesting protein localization on the cell surface. (C) At E12.0, an immunohistochemical signal is also present in the thickened area of the OPL and in the underlying mesenchymal cells. The Prtgexpressing is strong in the mesenchymal cells localized beneath the thickened OPL (indicated by the square). (D) A higher magnification of the boxed area in the Fig. 6C. (E) At E14.0, the Prtg expression is notable in the enamel organ and the surrounding mesenchymal cells. (G) At E16.0, immunohistochemical signals are marginally detected in the enamel organ and the dental papilla. $(\mathbf{F}, \mathbf{H})$ Higher magnifications of the boxed areas in the Figs. $6 \mathrm{E}$ and $\mathrm{G}$, respectively. (I) The immunohistochemical signal was detected in the dental papilla as well as in the enamel organ. (J) A higher magnification of the boxed area in the Fig. 6l. The left side of Figs. 6A, C, E, G and I corresponds to the lingual side, and the right side is the buccal side. Scale bars: A, C, E, G and I, $200 \mu \mathrm{m} ; \mathrm{B}, \mathrm{D}, \mathrm{F}, \mathrm{H}$ and J, $40 \mu \mathrm{m}$. 


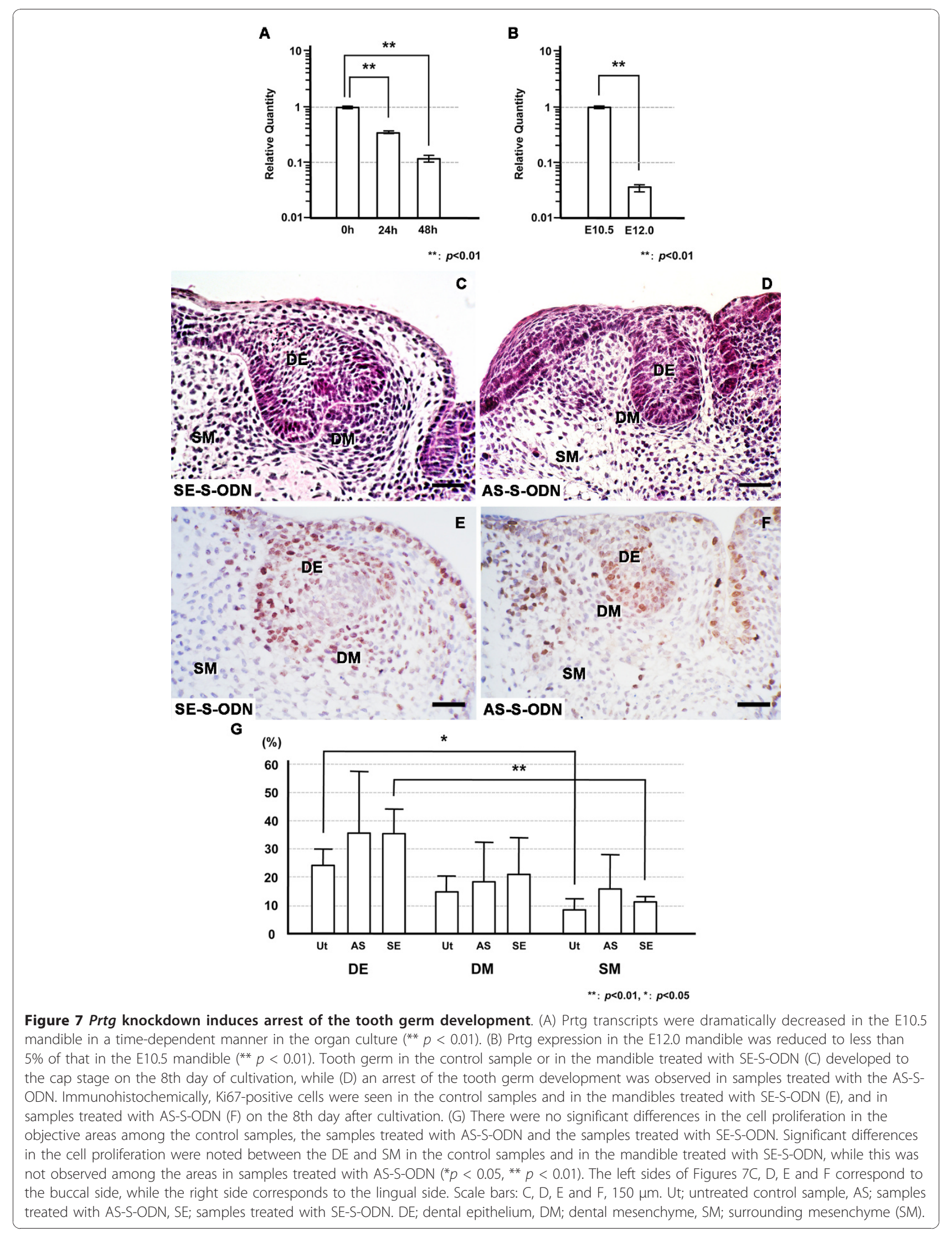


Table 1 The effects of Prtg knockdown on enamel organ formation in the cultured mandible

\begin{tabular}{cccccccccc}
\hline $\begin{array}{c}\text { Developmental } \\
\text { Stages }\end{array}$ & \multicolumn{2}{l}{ Untreated } & \multicolumn{2}{c}{ HVJ } & \multicolumn{2}{c}{ SE } & \multicolumn{2}{c}{ AS* } \\
\cline { 2 - 10 } & Bud & Cap & Bud & Cap & Bud & Cap & Bud & Cap \\
\hline Sample No. & 0 & 10 & 1 & 5 & 1 & 6 & 18 & 5 \\
$(\%)$ & $(0)$ & $(100)$ & $(17)$ & $(83)$ & $(14)$ & $(86)$ & $(78)$ & $(22)$ \\
\hline
\end{tabular}

$\left({ }^{*} p<0.05\right)$

The histological analysis was performed to evaluate the effects of Prtg knockdown on enamel organ formation in the cultured E10.5 mandibles after S-ODN treatment for 8 days. The development of the enamel organs on day 8 of culture was significantly inhibited.

the untreated mandibles and mandibles treated with only hemagglutinating virus of Japan (HVJ)-liposome (Table 1). The development of the enamel organs treated with Prtg AS-S-ODN on day 8 of culture was significantly inhibited in comparison to that in the other groups $(p<$ 0.05; Table 1).

A cell proliferation analysis was performed to address the involvement of Prtg in the tooth morphogenesis. The Ki67-positive ratio was evaluated in the cultured organs treated with AS-S-ODN for Prtg. In the cultured organs, the objective cells were examined in three areas; the "dental epithelium (DE)", "dental mesenchyme (DM)" and "surrounding mesenchyme (SM)". The DM was either the "dental papilla and follicle" in the cultured organs showing the normal cap-like tooth germ, or the "odontogenic ectomesenchyme" in the samples with the inhibition of tooth germ development. As shown in Figure 7G, no significant difference in the Ki67-positive ratio was observed in any of the objective areas (DE, DM or SM) between the control mandibles (Figure 7E) and the cultured mandibles at E10.5 treated with Prtg AS-S-ODN (Figure 7F). While significant differences in cell proliferation were noted between the DE and SM in the control sampled and in the mandibles treated with SE-S-ODN, this difference was not observed in the areas in samples treated with AS-SODN (Figure 7G). No apparent inhibition of cell proliferation by Prtg perturbation was observed in the samples at day 8 of culture in this study.

Down-regulation of Bmp-4 expression by the depletion of Prtg mRNA by AS-S-ODN

Based on the findings of the Prtg inhibition assay, we performed a real-time PCR analysis to examine Bmp-4, Fgf8, Lef-1, Pitx2 and Shh expression between AS-SODN-treated E10.5 mandibles and the others. These genes are expressed in mouse E10.5 mandible and are associated with odontogenesis [24-28]. The samples treated with S-ODN for $24 \mathrm{hr}$ were used to examine the changes in gene expression in the early phase after Prtg inhibition.
Mouse Gapdh was used as an internal control. At $24 \mathrm{hr}$ after AS-S-ODN treatment, Bmp-4 mRNA expression in the E10.5 mandible was reduced to approximately $40 \%$ by AS-S-ODN treatment, and was significantly lower with AS-S-ODN treatment than without treatment, than with RS-S-ODN treatment, or with SE-S-ODN treatment samples $(p<0.05, p<0.05$ and $p<0.01$, respectively; Figure 8 ). Meanwhile, the expression levels of Fgf8, Lef-1, Pitx2, and Shh showed no significant differences following treatment with Prtg AS-S-ODN (data not shown).

\section{Discussion}

This study showed that Prtg, which is a highly expressed gene in the E10.5 mouse mandible, using a cDNA subtraction method between mandibles at E10.5 and E12.0 [9]. The gene belongs to the immunoglobulin superfamily according to a structural analysis, and was expressed in the early stages of the developing tooth germ. The temporal and spatial expression of this gene suggested that this gene is involved in the development of the mouse lower first molar. This is the first report to describe the relationship between the expression of Prtg and tooth morphogenesis.

The amino acid alignment of Prtg is comprised of an SP, 4 Ig domains, 5 FNIII repeats, a single TM, and a $\mathrm{CD}$, thereby showing the typical structure of an IgSF. Treatment with N-glycosidase F revealed that Ptrg is a highly $\mathrm{N}$-glycosylated transmembrane protein. However, because the Prtg protein is bigger than the assumed size even after the treatment with $\mathrm{N}$-glycosidase, this modification is also associated with O-glycosylation and phosphorylation. The structural characteristics of Prtg are similar to DCC, Neogenin [17], Punc [18], and Nope

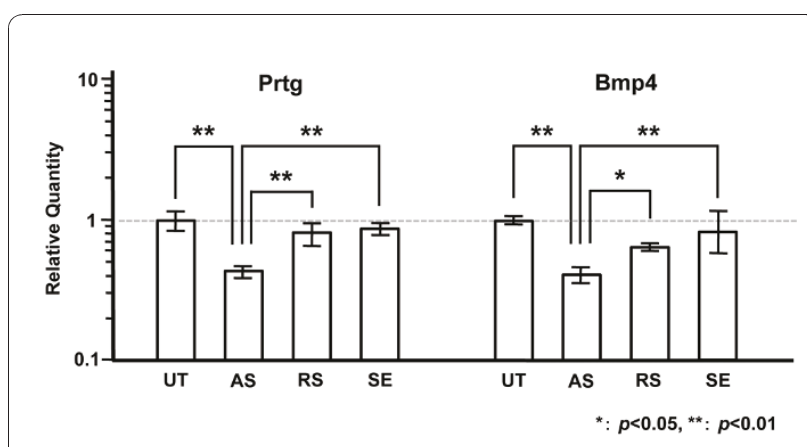

Figure 8 Prtg knockdown reduces the expression of odontogenesis-related genes. Bmp-4 expression was significantly downregulated after $24 \mathrm{hr}$ AS-S-ODN treatment in the cultured E10.5 mandibles. Significant differences in the transcription activity are indicated with either single or double asterisks $\left(^{*} p<0.05,{ }^{* *} p<\right.$ 0.01). Ut; untreated control sample, AS; samples treated with AS-SODN, RS; samples treated with random sequence-S-ODN, SE; samples treated with SE-S-ODN. 
[19], thus suggesting that they are all members of the DEAL subfamily.

Some IgSF proteins are important in the early developmental stage of the central nervous system. Meanwhile, these IgSF proteins are also implicated in various organs and tissues such as testis (BT-IgSF) [29], intestine (Neogenin) [17] and mesoderm cells (Robo) [30]. Chuong et al. [31] suggested that DCC may be involved in the differentiation of stem cells within several epithelial tissues. Nierhoff et al. [32] reported that the IgSF member Nope is expressed in rat fetal liver stem cells, and this gene might therefore be useful to identify, characterize, and isolate hepatic stem cells from the adult liver. Recently, diverse functions of DEAL have been identified, and include cell migration and axon growth guidance during development of the vertebrate nervous system [33-37] and the morphogenesis of epithelial tissues and the control of apoptosis in non-neural organization [17,31-33,38-40]. Therefore, it is likely that Prtg has multiple functions as a member of the DEAL family, including cell proliferation and cell differentiation during embryogenesis.

The RT-PCR and Western blot analyses showed that the Prtg mRNA and protein were expressed in the early developmental stages of tooth germ morphogenesis, as well as in the central nervous system. In the mouse, we did not detect Prtg mRNA in any adult tissues except for the brain, thus suggesting that Prtg function may be required in some non-neural tissues during organogenesis. The ISH and IHC results demonstrated that this gene was highly expressed in the epithelial and mesenchymal cells at E10.5, and this expression pattern is similar to the distribution of the arch ectodermal cells [14]. The first branchial arch is derived from neural crest cells [23]. Ptrg is strongly expressed in the first branchial arch in the early stage of embryogenesis (until E9.25) [14]. Because the mandible develops from the first branchial arch, the findings suggest that Prtg might play a role in the migration of neural crest cells, similar to the function of the other DEALs during development of the nervous system [33-37]. Tooth morphogenesis appears to begin with a signal of an epithelial-mesenchymal interaction [3-5]. The site where the tooth germ is likely to form is determined by the signal of mesenchymal cells which are derived from craniofacial neural crest cells [23]. The mesenchymal cells in the early phase (E10.5 and E12.0) of tooth germ formation were found to be positive for Prtg. This may indicate that the expression of Prtg is closely associated with epithelialmesenchymal interactions.

An interesting finding in this study revealed that Prtg was expressed in epithelial cells, including the estimated tooth germ formation area at E12.0, the epithelial cells of the tooth bud at E14.0, and the inner enamel epithelium at E18.0. The DEAL proteins have been observed in non-neural systems and are involved in the morphogenesis of epithelial tissues and the control of apoptosis during organization. In fact, there are reports describing their role in the differentiation of the intestine epithelium [41,42], and in the budding and branching of lung alveoli [39]. Therefore, it is reasonable to consider that Prtg is also involved in the early development of odontogenic epithelial tissue. Once the tooth developmental process is initiated, then Prtg expression may be dramatically downregulated in these regions. In this study, AS-S-ODN was employed in an organ culture system to examine the functional roles of Prtg in the development of the tooth germ. The development of tooth germ was arrested at the bud stage when AS-SODN was added to the culture media. However, Prtg perturbation did not lead to any apparent inhibition of cell proliferation in this study. The reason for the developmental arrest of the tooth remains unknown at present. It is possible that the result may have been observed because the comparison was made between the tooth germs with different developmental stages at the 8th day after cultivation of the controls or the samples treated with SE-S-ODN and the samples treated with Prtg AS-S-ODN. Recently, Wong et al. reported that Prtg might have the potential to act before the onset of circulation to coordinate the rate of proliferation and the time of differentiation between the three primary germ layers [43]. In our study, the expression level of Prtg markedly decreased after E12.0 in comparison to that at E10.5. Similar results were shown during nerve development in the study of Wong et al. [43]. Therefore, it seems likely that the Prtg participates in the development of the tooth germ during the process of odontogenesis.

Furthermore, Bmp-4 mRNA expression was decreased following Prtg depletion. This result suggests that the Prtg is related to the direct or indirect regulation of Bmp-4 gene transcription. Because Bmp-4 plays an important role during odontogenesis as well as embryogenesis [24,26], Prtg depletion by treatment with AS-S-ODN may induce developmental arrest of the tooth germ. However, there have been no reports thus far that describe the mechanism of Prtg regulation of Bmp-4 expression. The other genes, Fgf8, Lef-1, Pitx2, and Shh, also play important roles in determining and/or budding tooth germ in the early development. Bmp-4 induces Lef-1 expression [44]. Pitx2 transcription is partially regulated by Lef1 [45]. Meanwhile, the Lef-1 expression overlaps that of Pitx2 at approximately E1.5 after Pitx2 expression, and Pitx 2 regulates the Lef-1 isoform expression [46]. Interactions between these products are complex, and further studies will likely clarify the interrelationship between them and their role in development. Although Bmp-4 downregulation would be 
expected to extend to other genes, Prtg depletion did not significantly affect the expression of these genes in the early phase (within $24 \mathrm{hr}$ ). While Pitx-2 is expressed within the entire left atrial chamber of E12.5 mouse hearts [47], the Prtg protein is not detectable within cardiac cells of the atrial and ventricular chambers from E8.25 to E10.5 mouse hearts [43]. The interaction between Prtg and these proteins, and signal transduction pathways associated with Prtg have not been identified so far. Therefore, future studies will be needed to clarify the interaction between Prtg and Bmp-4 during signal transduction and subsequent gene expression, as well as that among the other genes during tooth germ development.

Alternatively spliced variants were not identified within the coding region of Prtg cDNA from E10.5 mice in this study. In contrast, mouse Neogenin (mNeogenin) has four alternatively spliced exons, three within the extracellular domain and a fourth within the cytoplasmic domain. Three of these alternatively spliced exons are developmentally regulated [48]. Interestingly, DCC also contains an alternatively spliced exon within the extracellular domain $[49,50]$. The expression of DCC with this alternative exon is also regulated throughout embryogenesis, as seen with the alternative forms of mNeogenin [51]. Thereafter, when more clones from various embryonic stages are analyzed, alternatively spliced forms of Prtg may be found in the neuron tissue. However, Prtg expression was dramatically downregulated in the tooth germ after E12. The regulation of Prtg function might therefore be different from the mechanism of DCC and Neogenin.

\section{Conclusion}

This study demonstrated that Ptrg is preferentially expressed in the early stage of organogenesis. This study characterized the expression pattern of Prtg in the developing tooth germ, and thus shows the possible functional implications of this gene in tooth germ morphogenesis through an inhibition assay for Prtg by AS-S-ODN in organ culture. Prtg, an IgSF family member is involved in the initial development of the tooth germ and in the differentiation of the inner enamel epithelial cells in the mouse lower first molar. Future investigations of organ cultures of the mandible earlier than E10.5 are therefore expected to clarify this process.

\section{Methods}

\section{Animals}

The embryos of BALB/c mice at E10.5, E12.0, E14.0, E16.0, and E18.0 after gestation were used in this study. The adult BALB/c mice were obtained from Charles River Laboratories (Charles River Japan Incorporated). Female BALB/c mice (10-30 weeks) were caged together with male mice. After $3 \mathrm{hr}$, successful insemination was determined based on the presence of a post-copulatory plug in the vagina. The embryonic day was defined as E0 after the post-copulatory plug was recognized. Male mice $(3,5$, and 10 weeks) were also used to examine the expression of Prtg. All mouse experiments and housing were performed in accordance with the guidelines of the Animal Center of Kyushu University.

\section{CDNA subtraction and cloning procedures}

Prtg was identified as a novel gene, termed Clone 15, in a previous study [9]. Based on the sequence of a fragment of this gene, 5'-/3'-RACE was performed to determine the full-length sequence (SMART RACE cDNA Amplification Kit; Clontech). Prtg DNA sequencing was performed with the dideoxynucleotide termination method using a DNA sequencer 373 S (Applied Biosystems). A search of the GenBank online database (using NCBI/BLAST/blastn suite: BLASTN programs) revealed no information at that time. In a later search, it corresponded with part of GenBank Accession numbers AK036172, AK083540, and NM_175485. AK036172 includes a polyadenylation signal site, and NM_175485 includes an arrangement of a signal peptide (SP). The sequencing data identically correlated to that of the recently updated NM_175485.4.

\section{Structural analysis based on the amino acid alignment}

A domain analysis of the Prtg protein sequence was carried out based on the amino acid alignment using an NCBI conserved domain search with the online NCBI program http://www.ncbi.nlm.nih.gov/Structure/cdd/ cdd.shtml. The signal peptides and a transmembrane region were predicted using the SOSUI system http:// bp.nuap.nagoya-u.ac.jp/sosui/.

\section{Intracellular localization of recombinant Prtg}

Three different plasmids expressing an EGFP-fusion protein were prepared. Prtg cDNA with a full-length, or the Prtg cDNA with a deleted SP1 or SP2 region were inserted in pEGFP-N1 vectors (Clontech), as shown in Figure 2A. These subcloned vectors were termed as Prtgfull, Ptrg- $\triangle$ SP1, and Prtg- $\triangle$ SP2. MISK81-5, which is an oral squamous cell carcinoma cell line established in our laboratory [22], was stably transfected with Prtg-full, Prtg- $\triangle S P 1$, Prtg- $\triangle$ SP2, or an empty vector using Lipofectamine 2000 (Invitrogen). These transfectants were isolated after selection with $800 \mu \mathrm{l} / \mathrm{ml}$ G418 for 2-3 weeks.

Immunofluorescent staining with an anti-cadherin antibody and Alexa Fluor 594 rabbit anti-mouse IgG (Invitrogen) was performed on the cells transfected with the Prtg-full plasmid. The fluorescent images were observed under a fluorescent microscope and acquired using the digital imaging software program, AxioVision version 3.1 (Carl Zeiss). 


\section{Specific antibodies against Ptrg}

Rabbit anti-Prtg polyclonal antibodies were generated against a synthetic peptide based on the regions as follows: 1) PKDASESNQRPKRLDSSNAKV (Entrez Protein database accession number NP_780694 aa 910-930), 2) STPPTSNPLAGGDSDGDAAPKKHGD (aa 11391163), and 3) DAAPKKHGDPAQPLPA (aa 1156-1171). The first amino acid sequence is present in the extracellular domain near the transmembrane region, whereas the two latter sequences correspond to sequences in the cytoplasmic domain. First, three antibodies were tested for their dye-affinity. The antibody for aa 1156-1171 was selected and used for all subsequent experiments because it gave a more specific signal.

\section{Western blot analysis}

A Western blot analysis for Prtg protein levels was performed on resolved proteins isolated from the homogenates of E10.5 and E12.0 mandibles and E18.0 tooth germ. These tissues were lysed in RIPA buffer $(50 \mathrm{mM}$ Tris $\mathrm{pH} 8.0,150 \mathrm{mM} \mathrm{NaCl}, 1 \%$ Triton X-100, $1 \mathrm{mM}$ EDTA pH 8.0, 0.1\% SDS) supplemented with a protease inhibitor cocktail $(50 \mu \mathrm{M})$, lactacystin $(20 \mu \mathrm{M})$, and PMSF. The protein samples were separated on a $7 \%$ SDS-polyacrylamide gel and electrotransferred to an Immun-Blot PVDF Membrane (Bio-Rad). The membrane was probed with antibody against Prtg for $1 \mathrm{hr}$ at room temperature, and incubated for $1 \mathrm{hr}$ with secondary anti-rabbit IgG conjugated with horseradish peroxidase (Amersham). The membrane was developed using the enhanced chemiluminescence (ECL) Plus system (Amersham). Emitted light was detected using a cooled CCD-camera (LAS-1000), (Fujifilm). Glycosidase digestion was performed with an N-glycosidase F deglycosylation kit (Roche) according to the manufacturer's instructions before loading the samples in the gel.

\section{Temporal expression analysis of Prtg mRNA by semi- quantitative RT-PCR}

Total mRNA was extracted from E10.5, E14.0, and E18.0 mice, and from various organs of the 3-, 5-, or 10-weekold mice using an SV Total RNA Isolation system (Promega). Reverse transcription was performed to synthesize cDNAs using the Superscript III reverse transcriptase (Invitrogen). The cDNAs were amplified by PCR to compare the expression with the manifestation quantity. The forward and reverse primer pairs for Prtg and glyceraldehyde-3-phosphate dehydrogenase (GAPDH) were: Prtg 5'-CGA AGC AAA GCC AGG AAG TC-3' and 5'-GCT TGT TGT GAA TCC CTG AGC G-3', and GAPDH 5'-ACC ACA GTC CAT GCC ATC AC-3' and 5'-TCC ACC ACC CTG TTG CTG TA-3'. The PCR products were separated by electrophoresis on a $2 \%$ agarose gel. To confirm that the PCR products were derived from cDNA and not from genomic DNA, the primer pairs were designed upstream and downstream of introns.

\section{In Situ Hybridization}

The section preparation, the probe labeling, the specificity of the DIG-labeled in situ RNA probes, and ISH methods were carried out as described in our previous studies $[6,7,12]$. Prtg antisense probes were designed against a sequence in the $\mathrm{C}$-terminal region and the 3'-UTR corresponding to nucleotide positions 3487 to 4917 (NM_175485.4). A Prtg sense probe was applied to the tissue specimens as a control. However, no hybridization signal was detected.

\section{Immunohistochemistry}

The preparation of serial cryosections was processed in the same way as for ISH. After the dried cryosections were rinsed with PBS containing 0.1\% Triton X-100 for $10 \mathrm{~min}$, and IHC was performed with a CSA II Biotinfree Tyramide Signal Amplification System according to the manufacturer's instructions (Dako). The primary anti-Prtg antibody diluted 1:500 in PBS was used. For the negative control, the application of the primary antibody was omitted from the procedure.

\section{Inhibition assay for Prtg by AS-S-ODN in organ culture}

The detailed procedures of the inhibition assay for Prtg by AS-S-ODN in organ culture have been shown in previous studies [6,7]. Briefly, the mandibles were dissected from E10.5 embryos. These explants were mounted on a filter $(0.8 \mu \mathrm{m}$ pore size, Millipore, MA), and then were incubated in Fitton-Jackson's modified BGJb medium (Invitrogen) supplemented with 5\% fetal bovine serum (Filtron, Brooklyn, Australia), $100 \mu \mathrm{g} / \mathrm{ml}$ ascorbic acid (Invitrogen), and 100 units $/ \mathrm{ml}$ penicillin/streptomycin (Invitrogen) in a $5 \% \mathrm{CO} 2$ atmosphere at $37^{\circ} \mathrm{C}[6,7]$.

The HVJ-liposomes (GenomeOne series, Ishihara Sangyo Kaisha, LTD., Osaka, Japan) were purchased for this study. The HVJ-liposome complex was prepared according to the manufacturer's instructions (Ishihara). ODNs were: sense-S-ODN (SE-S-ODN): 5'-TGA ATG GCG CCT CCC GT-3', antisense-S-ODN (AS-S-ODN): 5'ACG GGA GGC GCC ATT CA-3'. The SE/AS-S-ODNs corresponded to nucleotide positions 181-197 (GenBank accession number NM_175485.4). The treatment with AS- or SE-S-ODN or HVJ-liposome alone was performed at $24 \mathrm{hr}$ intervals.

\section{Histological analysis of cultured mandibles}

On the 8th day after cultivation, the cultured mandibles were fixed with $4 \%$ paraformaldehyde and embedded in paraffin to be used for histological analysis. Five- $\mu$ mthick sections were cut in an antero-posterior direction, 
and were stained in hematoxylin and eosin. The sections were examined under light microscopy.

\section{Cell proliferation analysis of the cultured organs treated with AS-S-ODN}

In order to address the involvement of the Prtg protein in tooth morphogenesis, a cell proliferation was analyzed in the cultured organs treated with AS-S-ODN for Prtg. Immunohistochemistry using a rabbit polyclonal antibody to the Ki67 (Abcam, Cambridge UK) was performed to evaluate Ki67-positive cells in the DE, DM and SM areas. More than one hundred objective cells were examined as a population in at least three different microscopic fields of each area. The number of the stained cells was divided by the total number of stained and nonstained target cells to calculate the Ki67-positive ratio.

\section{Effects of Prtg suppression by AS-S-ODN on odontogenesis-related gene transcription}

Real-time quantitative PCR was performed to estimate the subsequent expression of selected genes using Thermal Cycler Dice Real Time System (TaKaRa, Shiga, Japan) with SYBR Premix Ex Taq II (TAKARA) according to the manufacturer's instructions. At $24 \mathrm{hr}$ after the inhibition assay for Prtg by AS-S-ODN in organ culture, Bmp-4, Fgf8, Lef-1, Pitx2, and Shh were analyzed in this study. Gapdh was used as a referable gene. The specific primer sets were as follows:

Prtg forward 5'-ATC GCA GTA GGC GTT GGC ATA-3',

reverse 5'-CGC TGT CTT AGA GGC GGA TGA-3'.

Bmp-4 forward 5'-AGC CGA GCC AAC ACT GTG AG-3',

reverse 5'-TCA CTG GTC CCT GGG ATG TTC-3'.

Fgf8 forward 5'-CAT CAA CGC CAT GGC AGA A-3',

reverse 5'-TCT CCA GCA CGA TCT CTG TGA ATA C-3'.

Lef1 forward 5'-TCA CTG TCA GGC GAC ACT TC-3', reverse 5'-TGA GGC TTC ACG TGC ATT AG-3'.

Pitx2 forward 5'-AGC TGT GCA AGA ATG GCT TT-3,

reverse 5'-CAC CAT GCT GGA CGA CAT AC-3'.

Shh forward 5'-AGC AGA CCG GCT GAT GAC TC-3', reverse 5'-TCA CTC CAG GCC ACT GGT TC-3'.

Gapdh forward 5'-TGT GTC CGT CGT GGA TCT GA-3',

reverse 5'-TTG CTG TTG AAG TCG CAG GAG-3'.

The relative expression levels of each targeted gene were normalized using the $\Delta \Delta \mathrm{C}_{\mathrm{T}}$ comparative method, based on the referable gene threshold cycle (CT) values [52].

\section{Statistical analysis}

Significant differences within a group and between groups were determined by a chi-square test for the independence of the Prtg inhibition assay, and by unpaired Student's t-test or one-way ANOVA with the Tukey-Kramer comparison test for real-time PCR data and cell proliferation assay using the Statcel2 software program. When necessary, Welch's t-test was used for unequal variances. A $P$-value of less than 0.05 or 0.01 was considered to be statistically significant.

\section{Acknowledgements}

The authors would like to thank Mrs. S. Ono for the excellent technical assistance in this study. The authors also would like to thank Dr. K. Matsuo for valuable discussions. This research was funded in part by Grant-in-Aid from the Ministry of Education, Culture, Sports, Science and Technology of Japan, to H.S. (\#17390487 and \#20390466).

\section{Author details}

'Laboratory of Oral Pathology and Medicine, Faculty of Dental Science, Kyushu University, Fukuoka 812-8582, Japan. ${ }^{2}$ Department of Prosthodontics, School of Stomatology, Ninth People's Hospital, Shanghai Jiao Tong University, 639 Zhizaoju Road, Shanghai, 200011, China. ${ }^{3}$ Department of Pediatric Dentistry, Faculty of Dental Science, Kyushu University, Fukuoka 812-8582, Japan. ${ }^{4}$ Department of Fixed Prosthodontics, Faculty of Dental Science, Kyushu University, Fukuoka 812-8582, Japan.

\section{Authors' contributions}

KFT and TK carried out the experimental work. KFT performed the immunoassays, in situ hybridization and the organ culture studies. KFT also helped to draft the manuscript. TK carried out the molecular genetic studies, and performed the statistical analysis. TK also participated in the design of the study and coordination, and helped to draft the manuscript. IK, MX, HF, YO and HW helped to conduct the organ culture studies with AS-S-ODN, and helped to make the histological analysis. HY participated in the sequence alignment and structure analysis. IK, KN and HW participated in the histological analysis and cell proliferation analysis. TS and YT helped to review the data. HS conceived the study, participated in its design and coordination, and drafted the manuscript. All authors read and approved the final manuscript.

Received: 7 June 2010 Accepted: 25 November 2010 Published: 25 November 2010

\section{References}

1. Maas R, Bei M: The genetic control of early tooth development. Crit Rev Oral Biol Med 1997, 8:4-39.

2. Thesleff I, Åberg T: Molecular regulation of tooth development. Bone 1999, 25:123-125.

3. Jernvall J, Thesleff I: Reiterative signaling and patterning during mammalian tooth morphogenesis. Mech Dev 2000, 92:19-29. 
4. Pispa J, Thesleff I: Mechanisms of ectodermal organogenesis. Dev Biol 2003, 262:195-205

5. Thesleff I: Epithelial-mesenchymal signalling regulating tooth morphogenesis. J Cell Sci 2003, 116:1647-1648.

6. Kobayashi I, Kiyoshima T, Wada H, Matsuo K, Nonaka K, Honda JY, Koyano K, Sakai H: Type II/III Runx2/Cbfa1 is required for tooth germ development. Bone 2006, 38:836-844.

7. Xie M, Kobayashi I, Kiyoshima T, Yamaza H, Honda JY, Takahashi K, Enoki N, Akamine A, Sakai H: Functional implication of nucleolin in the mouse first molar development. J Biol Chem 2007, 282:23275-23283.

8. Honda JY, Kobayashi I, Kiyoshima T, Yamaza H, Xie M, Takahashi K, Enoki N, Nagata K, Nakashima A, Sakai H: Glycolytic enzyme Pgk1 is strongly expressed in the developing tooth germ of the mouse lower first molar. Histol Histopathol 2008, 23:423-432.

9. Yamaza H, Matsuo K, Kiyoshima T, Shigemura N, Kobayashi I, Wada H, Akamine A, Sakai H: Detection of differentially expressed genes in the early developmental stage of the mouse mandible. Int J Dev Biol 2001, 45:675-680

10. Yamaza H, Matsuo K, Kobayashi I, Wada H, Kiyoshima T, Akhtar M, Ishibashi Y, Sakai T, Akamine A, Sakai H: Expression of Set-alpha during morphogenesis of mouse lower first molar. Histochem J 2001, 33:437-441.

11. Wada H, Kobayashi I, Yamaza H, Matsuo K, Kiyoshima T, Akhtar M, Sakai T, Koyano K, Sakai H: In situ expression of heat shock proteins, Hsc73, Hsj2 and Hsp86 in the developing tooth germ of mouse lower first molar. Histochem J 2002, 34:105-109.

12. Akhter M, Kobayashi I, Kiyoshima T, Matsuo K, Yamaza H, Wada H, Honda JY, Ming X, Sakai H: Possible functional involvement of thymosin beta 4 in developing tooth germ of mouse lower first molar. Histochem Cell Biol 2005, 124:207-213.

13. Toyoda R, Nakamura H, Watanabe Y: Identification of protogenin, a novel immunoglobulin superfamily gene expressed during early chick embryogenesis. Gene Expr Patterns 2005, 5:778-785.

14. Vesque C, Anselme I, Couvé E, Charnay P, Schneider-Maunoury S: Cloning of vertebrate Protogenin (Prtg) and comparative expression analysis during axis elongation. Dev Dyn 2006, 235:2836-2844.

15. Crossin KL, Krushel LA: Cellular signaling by neural cell adhesion molecules of the immunoglobulin superfamily. Dev Dyn 2000, 218:260-279

16. Barclay AN: Membrane proteins with immunoglobulin-like domains-a master superfamily of interaction molecules. Semin Immunol 2003, 15:215-223.

17. Vielmetter J, Kayyem JJ, Roman JM, Dreyer WJ: Neogenin, an avian cell surface protein expressed during terminal neuronal differentiation, is closely related to the human tumor suppressor molecule deleted in colorectal cancer. J Cell Biol 1994, 127:2009-2020.

18. Salbaum JM: Genomic structure and chromosomal localization of the mouse gene Punc. Mamm Genome 1999, 10:107-111.

19. Salbaum JM, Kappen C: Cloning and expression of nope, a new mouse gene of the immunoglobulin superfamily related to guidance receptors. Genomics 2000, 64:15-23.

20. Fearon ER, Cho KR, Nigro JM, Kern SE, Simons JW, Ruppert JM, Hamilton SR, Preisinger AC, Thomas G, Kinzler KW, Vogelstein B: Identification of a chromosome 18q gene that is altered in colorectal cancers. Science 1990, 247:49-56.

21. Yang W, Li C, Mansour SL: Impaired motor coordination in mice that lack punc. Mol Cell Biol 2001, 21:6031-6043.

22. Matsuo K, Ishibashi Y, Kobayashi I, Ozeki S, Ohishi M, Tange T, Hirata J, Sakai H: New human oral squamous carcinoma cell line and its tumorigenic subline producing granulocyte colony-stimulating factor. Jpn J Cancer Res 1994, 85:1257-1262.

23. Chai $Y$, Jiang $X$, Ito $Y$, Bringas $P$ Jr, Han J, Rowitch DH, Soriano $P$, McMahon AP, Sucov HM: Fate of the mammalian cranial neural crest during tooth and mandibular morphogenesis. Development 2000, 127:1671-1679.

24. Vainio S, Karavanova I, Jowett A, Thesleff I: Identification of BMP-4 as a signal mediating secondary induction between epithelial and mesenchymal tissues during early tooth development. Cell 1993, 75:45-58.

25. van Genderen C, Okamura RM, Fariñas I, Quo RG, Parslow TG, Bruha L, Grosschedl R: Development of several organs that require inductive epithelial-mesenchymal interactions is impaired in LEF-1-deficient mice. Genes Dev 1994, 8:2691-2703.

26. Neubüer A, Peters H, Balling R, Martin GR: Antagonistic interactions between FGF and BMP signaling pathways: a mechanism for positioning the sites of tooth formation. Cell 1997, 90:247-255.

27. Mucchielli ML, Mitsiadis TA, Raffo S, Brunet JF, Proust JP, Goridis C: Mouse Ot|x2/RIEG expression in the odontogenic epithelium precedes tooth initiation and requires mesenchyme-derived signals for its maintenance. Dev Biol 1997, 189:275-284.

28. Keränen SV, Kettunen P, Åberg T, Thesleff I, Jernvall J: Gene expression patterns associated with suppression of odontogenesis in mouse and vole diastema regions. Dev Genes Evol 1999, 209:495-506.

29. Suzu S, Hayashi Y, Harumi T, Nomaguchi K, Yamada M, Hayasawa H, Motoyoshi K: Molecular cloning of a novel immunoglobulin superfamily gene preferentially expressed by brain and testis. Biochem Biophys Res Commun 2002, 296:1215-1221.

30. Kramer SG, Kidd T, Simpson JH, Goodman CS: Switching repulsion to attraction: changing responses to slit during transition in mesoderm migration. Science 2001, 292:737-740.

31. Chuong CM, Jiang TX, Yin E, Widelitz RB: CDCC (chicken homologue to a gene deleted in colorectal carcinoma) is an epithelial adhesion molecule expressed in the basal cells and involved in epithelial-mesenchymal interaction. Dev Biol 1994, 164:383-97.

32. Nierhoff D, Levoci L, Schulte $S$, Goeser T, Rogler LE, Shafritz DA: New cell surface markers for murine fetal hepatic stem cells identified through high density complementary DNA microarrays. Hepatology 2007, 46:535-547.

33. Llambi F, Causeret F, Bloch-Gallego E, Mehlen P: Netrin-1 acts as a survival factor via its receptors UNC5 H and DCC. EMBO J 2001, 20:2715-2722.

34. Murase S, Horwitz AF: Deleted in colorectal carcinoma and differentially expressed integrins mediate the directional migration of neural precursors in the rostral migratory stream. J Neurosci 2002, 22:3568-3579.

35. Mehlen P, Mazelin L: The dependence receptors DCC and UNC5 $\mathrm{H}$ as a link between neuronal guidance and survival. Biol Cell 2003, 95:425-436.

36. Round J, Stein E: Netrin signaling leading to directed growth cone steering. Curr Opin Neurobiol 2007, 17:15-21.

37. Yamashita T, Mueller BK, Hata K: Neogenin and repulsive guidance molecule signaling in the central nervous system. Curr Opin Neurobiol 2007, 17:29-34.

38. Srinivasan K, Strickland P, Valdes A, Shin GC, Hinck L: Netrin-1/neogenin interaction stabilizes multipotent progenitor cap cells during mammary gland morphogenesis. Dev Cell 2003, 4:371-382.

39. Liu Y, Stein E, Oliver T, Li Y, Brunken WJ, Koch M, Tessier-Lavigne M, Hogan BL: Novel role for Netrins in regulating epithelial behavior during lung branching morphogenesis. Curr Biol 2004, 14:897-905.

40. Wilson NH, Key B: Neogenin: one receptor, many functions. Int I Biochem Cell Biol 2007, 39:874-878.

41. Fearon ER, Cho KR: Cancer: cell survival guide. Nature 2004, 431:35-36.

42. Mazelin L, Bernet A, Bonod-Bidaud C, Pays L, Arnaud S, Gespach C, Bredesen DE, Scoazec JY, Mehlen P: Netrin-1 controls colorectal tumorigenesis by regulating apoptosis. Nature 2004, 431:80-84.

43. Wong YH, Lu AC, Wang YC, Cheng HC, Chang C, Chen PH, Yu JY, Fann MJ: Protogenin defines a transition stage during embryonic neurogenesis and prevents precocious neuronal differentiation. J Neurosci 2010, 30:4428-39.

44. Kratochwil K, Dull M, Farinas I, Galceran J, Grosschedl R: Lef1 expression is activated by BMP-4 and regulates inductive tissue interactions in tooth and hair development. Genes Dev 1996, 10:1382-94.

45. Ai D, Wang J, Amen M, Lu MF, Amendt BA, Martin JF: Nuclear factor 1 and T-cell factor/LEF recognition elements regulate Pitx2 transcription in pituitary development. Mol Cell Biol 2007, 27:5765-75.

46. Amen M, Liu X, Vadlamudi U, Elizondo G, Diamond E, Engelhardt JF, Amendt BA: PITX2 and beta-catenin interactions regulate Lef-1 isoform expression. Mol Cell Biol 2007, 27:7560-73.

47. Franco D, Campione M, Kelly R, Zammit PS, Buckingham M, Lamers WH, Moorman AF: Multiple transcriptional domains, with distinct left and right components, in the atrial chambers of the developing heart. Circ Res 2000, 87:984-91.

48. Keeling SL, Gad JM, Cooper HM: Mouse Neogenin, a DCC-like molecule, has four splice variants and is expressed widely in the adult mouse and during embryogenesis. Oncogene 1997, 15:691-700. 
49. Reale MA, Hu G, Zafar Al, Getzenberg RH, Levine SM, Fearon ER: Expression and alternative splicing of the deleted in colorectal cancer (DCC) gene in normal and malignant tissues. Cancer Res 1994, 54:4493-501.

50. Cooper HM, Armes P, Britto J, Gad J, Wilks AF: Cloning of the mouse homologue of the deleted in colorectal cancer gene (mDCC) and its expression in the developing mouse embryo. Oncogene 1995, 11:2243-54.

51. Slavkin H, Nuckolls G, Shum L: Craniofacial development and patterning (2000). Methods Mol Biol 2000, 136:45-54.

52. Yuan JS, Reed A, Chen F, Stewart CN Jr: Statistical analysis of real-time PCR data. BMC Bioinformatics 2006, 7:85.

doi:10.1186/1471-213X-10-115

Cite this article as: Takahashi et al:: Protogenin, a new member of the immunoglobulin superfamily, is implicated in the development of the mouse lower first molar. BMC Developmental Biology 2010 10:115.

Submit your next manuscript to BioMed Central and take full advantage of:

- Convenient online submission

- Thorough peer review

- No space constraints or color figure charges

- Immediate publication on acceptance

- Inclusion in PubMed, CAS, Scopus and Google Scholar

- Research which is freely available for redistribution

Submit your manuscript at www.biomedcentral.com/submit
C Biomed Central 